\title{
Health, Longevity, and the Role of the Family in China
}

\author{
Maria Porter
}

Received: 1 February 2011 / Accepted: 28 February 2011 / Published online: 26 March 2011

(C) Springer Science+Business Media B.V. 2011

China's population has been rapidly ageing as a result of significant advances in life expectancy and restrictive fertility policies in the past several decades. As a result, China will be the first developing country with a significantly ageing population. By 2050 , over $30 \%$ of the population will be 60 years old or older.

This ageing trend presents a number of challenges to a country with a developing economy. How will the ever increasing numbers of elderly people be supported by a shrinking workforce? Will public transfers be required, or will elderly people continue to rely on their children for support? How will such support be affected by increasing out-migration of children from rural areas to coastal cities? What about those elderly people who are widowed? How might losing a spouse affect one's health? What other factors affect elderly health and longevity? To what extent does income, education, or one's health early in life, perhaps even at birth, determine one's long-term health in old age or even the likelihood one will reach old age? The contributors to this special issue have taken important steps forward to begin addressing these questions.

This special issue is comprised of articles across several disciplines: economics, sociology, and bio-demography. Although researchers across these disciplines approach problems differently and use varying methodologies, I will show below that they also complement one another, and together, provide important steps forward in not only addressing issues facing China's ageing population, but also in advancing a research agenda more broadly on the determinants of health and longevity, as well as the role of the family in supporting elderly people.

The articles in this special issue also provide excellent examples of how we can use unique datasets to address important issues related to health and ageing in a developing country such as China. The Chinese Longitudinal Healthy Longevity Survey (CLHLS) is a panel survey which originally focused on those ages 80 and above, and since 2002, has surveyed respondents ages 65 and above. It includes the

M. Porter $(\bowtie)$

Oxford Institute of Ageing, University of Oxford, Oxford, UK

e-mail: maria.porter@ageing.ox.ac.uk 
largest sample of centenarians in the world. The China Health and Retirement Longitudinal Study (CHARLS) promises to be another rich data source for studying ageing-related issues in China, as it will be a nationally representative panel survey of all those ages 45 and above. It has been modeled after the Health and Retirement Study (HRS) in the US, and will be comparable to other longitudinal ageing surveys in the UK, continental Europe, Japan, South Korea, and India. Particularly as both CLHLS and CHARLS are publicly available, such datasets not only promote a promising research agenda on health and ageing in China, but also provide the opportunity to contribute more broadly to the interdisciplinary field of health and population ageing. As other developing countries will shift in their demographic transition to an ageing population, such research in China will provide a useful starting point for addressing the needs of these countries as well.

\section{Determinants of Health and Longevity}

Economic development has often been thought of as a precursor to better health. Wealthier and better educated individuals have the knowledge and means to take better care of themselves. Malnutrition predominates in low-income countries. Indeed, China has seen a decline in malnutrition rates among its population. Yet, prevalence rates of obesity and overweight adults have also increased sharply (Wang et al. 2007). Overweight adults are at greater risk of diabetes and hypertension. This poses a challenge for China, where advances in battling infectious diseases have propelled life expectancy at unprecedented rates (Riley 2004). China's healthcare system had not been set up to address non-communicable diseases, as evidenced by Strauss et al.'s finding that hypertension is severely under-diagnosed in Gansu and Zhejiang (Paper \#1). Indeed, chronic diseases account for $80 \%$ of China's current deaths (Wang et al. 2005).

In addition, rapid urbanization, a byproduct of China's economic growth, has been linked to higher rates of diabetes, tobacco use, poorer nutrition, less physical activity, obesity and hypertension (Wang et al. 2005). As urbanization is positively correlated with education, one might infer that education may be negatively related to health outcomes. Yet, Strauss et al. (Paper \#1) find that education is positively correlated with improved health outcomes. Certainly, better educated individuals would be better equipped to invest in their health, eating more nutritious foods, exercising more, engaging in less risky labor activities, and regularly visiting a doctor.

Yet, health and nutrition, particularly early in life, also play an important role in affecting education and labor market outcomes. Most notably, those affected by the Great Famine, by being exposed to malnutrition early in life, experienced negative schooling and labor market outcomes later in life (Chen and Zhou 2006; Almond et al. 2007; Meng and Qian 2009; Mu and Zhang 2011). More generally, lower birth weight babies experience worse health outcomes later in life, as evidenced in Zeng et al.'s findings in China (Paper \#2).

While Strauss et al. (Paper \#1) focus on the correlation between long-term health and socio-economic status, Zeng et al. (Paper \#2) emphasize the correlation between birth weight and long-term health. In fact, these two studies are very much related, as 
recent research points to birth weight being highly related to the health and wellbeing of one's mother.

For example, Barker et al. (2010) has found that the extent to which birth weight influences the likelihood of hypertension later in life depends on one's mother's height and socio-economic status. The authors found that hypertension later in life is more prevalent among those who were low birth weight babies. Birth weight depends not only on the body size of one's mother, but also on the surface area and weight of her placenta. This correlation was strongest among those whose mothers were of below-average height or low socio-economic status. Thus, poor maternal nutrition (which may be due to low socio-economic status) compounds negative effects of a small placenta while in-utero, and these effects persist throughout one's life.

Similarly, Eriksson et al. (2009) compared attributes of placentas at birth across male and female births. They found that male and female fetuses have different relationships with their mothers' placentas while in the womb, and that these differences may explain why men have higher rates of hypertension and lower life expectancy. Although male fetuses are more dependent on their mothers' diets, female fetuses are more dependent on their mothers' protein metabolism. The male strategy makes boys better able to take advantage of improvements in a mother's diet, but they are also more vulnerable when food becomes scarce.

This research provides a potential link between the findings of Strauss et al. (Paper \#1) and Zeng et al. (Paper \#2), and presents an opportunity for future research into the determinants of health and longevity. To what extent can one's long-term health be explained by one's own socio-economic status or by that of one's mother? To what extent does a woman's long-term health, SES, or diet while pregnant determine the long-term health of her offspring? Addressing these research questions would help explain the underlying mechanisms driving the findings in Strauss et al. (Paper \#1) and Zeng et al. (Paper \#2). Researchers working in ageing, health, and longevity know that SES and early life conditions are important determinants of health later in life. To what extent might intergenerational transmission of health explain correlates between SES or early life conditions and health? This presents an important research opportunity in the field of health and ageing.

\section{The Role of the Family in Providing Elderly Support}

Zhu and Gu (Paper \#3) demonstrate that conditions in old age may also play an important role in determining long-term health and longevity. Prior sociological research has shown that married individuals are healthier and live longer than those who are unmarried, particularly men (e.g., Waite and Gallagher 2000).

Using a unique panel dataset in China, Zhu and Gu (Paper \#3) demonstrate that this is also the case for those ages 80 and above. They also go further, finding that marital quality and duration are also positively correlated with health and longevity for the oldest old. In addition, those who have been widowed for a longer period of time are also less healthy. There are a number of possible explanations for these findings. In addition to the sociological literature discussed in Zhu and $\mathrm{Gu}$ (Paper \#3), economists have also studied the potential benefits of marriage. 
Economists refer to 'marital surplus' as the added benefit husband and wife jointly receive from being married to one another rather than remaining single (Becker 1973, 1991). Such a surplus is derived from sharing in responsibilities at home, which then allow for them to also earn more income, as well as provide care for children. But this surplus may also be derived from providing care for one another, and ensuring that each receives appropriate health care and maintains a healthy diet. It is perhaps not surprising that men's health is more positively related to marital status than women's health, as women are often tasked with ensuring their families eat well and receive proper health care.

This is evidenced by the fact that married individuals are more likely to die in a hospital, according to the CLHLS. Widowers die at home more often. This data also implies that married individuals spend more on health care than their single counterparts. Among rural respondents in the CLHLS, married women spend around $34 \%$ of their income on medical expenses, whereas widowed women spend $21 \%$ of their income (Porter 2011).

In addition, those who become widowed or divorced often draw down a significant portion of their assets, and this evolution of assets is strongly correlated with health (Poterba et al. 2009). Thus, one mechanism through which marital status might affect health may be through the drawing down of assets because of a negative event such as divorce or the death of one's spouse. Both events are also considerably costly, often involving costly legal fees, repayment of health expenses in the last several months of life, and funeral expenses. Disentangling the link between assets and health presents opportunities for future research in health and ageing.

A particularly important avenue for ageing researchers is the question of whether and how elderly people are equipped to deal with unexpected falls in income and wealth. This is a particularly salient issue for developing countries such as China, where an increasingly ageing population lacks a public system providing health care or financial support.

For many, children provide the primary means of support. Giles, Wang, and Zhao (Paper \#4) focus on this aspect of support for elderly people in China, and they examine differences between those elderly people with children who have migrated to cities for employment, to those with non-migrant children.

As it is becoming more common for children to migrate to cities, it is also becoming more common for rural elderly people to live on their own or to live further away from their children. Giles, Wang, and Zhao (Paper \#4) find that those with migrant children are more likely to fall into poverty than those who do not have migrant children, because the predicted variance of transfers received from migrant children is higher than that of non-migrant children. Migrant children often return to take care of parents when they are ill (Giles and $\mathrm{Mu}$ 2007). But living further away from parents may reduce the amount of contact parents receive from children.

In addition, families in particularly dire situations may be more likely to send their children to search for work in the cities than those who are better off. This might in part explain the correlation between having migrant children and the risk of falling into poverty.

Similarly, the link between marital status and health may also in part be explained by marriage selection. Men and women choose their spouses based on a host of characteristics, only some of which are observable to the researcher. For example, 
men tend to marry women who are of similar height, education, income, and health. Thus, healthier men would marry healthier women. As women tend to outlive men, those women whose husbands die at a relatively younger age may have had relatively less healthy husbands, in part because they may be similarly less healthy on average. Further, men who outlive their spouses may have married particularly less healthy women, in part because they themselves are less healthy.

Delineating between these marriage selection patterns and the benefits from marriage provide numerous opportunities for future research. Likewise, opportunities for research are at hand in disentangling the reasons one might choose to send children to cities as migrant workers from the negative impact of having children living further away.

\section{Policy Implications}

As previously mentioned, chronic diseases have become increasingly prevalent over the years as China's population grows older, wealthier, and becomes more urbanized. In particular, heart disease, stroke, and diabetes lead to higher health care costs, as well as negative consequences for savings rates and labour supply. Wang et al. (2005) estimated that between 2005 and 2015, the cumulative cost of such chronic diseases to the economy would be approximately $\$ 556$ billion.

Strauss et al. (Paper \#1) show that in addition to socio-economic status, unobserved differences across communities are also strong determinants of health outcomes for those ages 45 and above living in Gansu and Zhejiang. Researchers and policy-makers must focus on policies that will improve access and quality of health care across different communities. As suggested by Strauss et al. (Paper \#1), improvements in diagnosis, particularly of hypertension, would be an important step forward.

One possible explanation for such variations across communities may be differences in diet. Those living in colder climates tend to consume more fatty diets. Local price variation for foods has also been shown to affect variation in diets across communities. Lu and Goldman (2010) found that lower prices for energydense food resulted in higher body fat in China. Thus, subsidies of healthier foods or taxes on fatty foods may be one policy measure that can reduce the prevalence of overweight individuals.

In addition, pilot programs addressing chronic diseases have shown significant impact. One trial intervention in communities across Beijing, Shanghai, and Changsha addressed the management of diabetes and hypertension. Between 1991 and 2000 , the mortality rate and incidence of stroke declined by over $50 \%$. The World Bank initiated a disease prevention project in seven cities. In Beijing, diagnosis and treatment of hypertension increased and death rates from cardiovascular disease declined by more than 15\%. In 1997, the Ministry of Health began implementing community-based measures to prevent and control chronic disease nation-wide. These measures included community interventions to: curb smoking; promote a healthy diet and physical activity; prevent hypertension; improve mental health; prevent and control cardiovascular disease, diabetes, cancer, and chronic respiratory disease; and evaluate such interventions. Other government programs 
have focused on primary school education to reduce child obesity, as well as campaigns to reduce smoking (Wang et al. 2005). These programs have been important initial steps forward. Yet, a great deal more needs to be done, particularly in promoting education on health care and in improving access to primary care.

However, in light of the fact that fetal health is an important determinant of longterm health (Zeng et al., Paper \#2), we must ask-are community-based interventions the most effective means of improving long-term health and reducing death rates from chronic disease? Perhaps improving pre-natal and neo-natal care will have more long-term benefits for the health of China's population. A less sanguine view would go further - as birth weight and its relationship with long-term health varies with the health and SES of one's mother (Eriksson et al. 2009; Barker et al. 2010), perhaps pre-natal interventions come too late. On the other hand, policies aimed at promoting the health and well-being of today's population may also improve the long-term health and longevity of future generations.

Widowed men, particularly those living in rural areas, are at greater risk of dying. Why is this the case? What kinds of policies can promote their health and longevity? Further research is needed to determine the mechanisms behind this link between health and marital status. Perhaps, as has been found in the U.S., the unexpected illness and death of a spouse results in significant expenses that necessitate drawing down one's assets. Perhaps, this decline in wealth leads to less access to health care, medicine, or healthy living conditions. If future research finds this to be the case, then health insurance, and insurance against negative shocks may be a useful policy. Alternatively, it may be the case that spouses provide one another with support that promotes health, and that there are no good substitutes for such support in the market. In this case, nursing homes, other elderly residence facilities, or home health care providers for the widowed may be necessary.

The relationship between marital status and health later in life will become a particularly salient issue for China as those affected by the One Child Policy grow older. As this policy restricts many families to having one child, and as parents have a strong preference for sons, high sex ratios have resulted, and many men will remain unmarried (Ebenstein and Sharygin 2009). For this reason, the research findings highlighted by Zhu and Gu (Paper \#3) on the link between marriage and health are particularly important in considering future challenges facing China's elderly population.

Adult children are still an important source of support for elderly people in China. Yet Giles, Wang, and Zhao (Paper \#4) have shown that children do not fully insure their parents against poverty, particularly those that have migrated to the cities. With migration restrictions being relaxed, more people are moving to the cities and leaving their ageing parents behind. What kind of support system can the state provide that would address the needs of elderly people without crowding out private transfers received from children? What sort of policies can address the needs of rural elderly people whose children are far away?

Perhaps providing access to health care and housing for elderly parents of migrant workers in the cities will make it easier for children to care for their parents. But cities are already facing the challenge of absorbing an ever increasing migrant population. Also, migrants often work long hours and may not have time to provide support other than financial means. Migrant workers might also not have the 
financial means to support co-resident parents in cities where the cost of living is more expensive than in their rural homes. They are also at risk of unemployment. Having parents in rural villages gives migrants a place to return to if they have difficulty finding a job in the city.

Perhaps providing support to elderly parents may be a better way to address these challenges. This might also make it more cost-effective to address the needs of childless rural elderly people as well, as there are economies of scale to supporting an evergrowing ageing population. China's 12th Five Year Plan may address some of these issues, as a new rural pension scheme will be expanded to cover all rural areas by 2016.

The implementation of such elder support policies should be informed by ongoing research on the determinants of health and longevity, as well as on the role of the family in providing support to elderly people. The Journal of Population Ageing aims to publish theoretical and empirical research which may inform such policies. The contributions that the papers in this special issue offer exemplify such aims and the role such an approach may play in developing new strategies for the challenges of global ageing.

\section{References}

Almond, D., Edlund, L., Li, H., \& Zhang, J. (2007). Long-term effects of the 1959-1961 China famine: Mainland China and Hong Kong. NBER Working Paper No. 13384.

Barker, D. J. P., Thornburg, K. L., Osmond, C., Kajantie, E., \& Eriksson, J. G. (2010). The surface area of the placenta and hypertension in the offspring in later life. International Journal of Developmental Biology, 54(2,3), 525-530.

Becker, G. S. (1973). A theory of marriage: part I. Journal of Political Economy, 81, 813-846.

Becker, G. S. (1991). A treatise on the family. Cambridge: Harvard University Press.

Chen, Y., \& Zhou, L.-A. (2006). The long-term health and economic consequences of the 1959-1961 famine in China. Journal of Health Economics, 26(4), 659-681.

Ebenstein, A. Y., \& Sharygin, E. J. (2009). The consequences of the 'missing girls' of China. World Bank Economic Review, 23(3), 399-425.

Eriksson, J. G., Kajantie, E., Osmond, C., Thornburg, K., \& Barker, D. J. P. (2009). Boys live dangerously in the womb. American Journal of Human Biology, 22(3), 330-335.

Giles, J., \& Mu, R. (2007). Elderly parent health and the migration decision of adult children: evidence from rural China. Demography, 44(2), 265-288.

Lu, Y., \& Goldman, D. (2010). The effects of relative food prices on obesity-evidence from China: 1991-2006. NBER Working Paper No. 15720.

Meng, X., \& Qian, N. (2009). The long term consequences of famine on survivors: evidence from a unique natural experiment using China's great famine. NBER Working Paper No. 14917.

Mu, R., \& Zhang, X. (2011). Why does the Great Chinese Famine affect the male and female survivors differently? Mortality selection versus son preference. Economics and Human Biology, 9(1), 92-105.

Porter, M. (2011). Marriage in China and the elderly. In K. Eggleston \& S. Tuljapurkar (Eds.), Aging Asia: Economic and social implications of rapid demographic change in China, Japan, and Korea. Washington: Brookings Institution Press.

Poterba, J., Venti, S., \& Wise, D. A. (2009). Family status transitions, latent health, and the post-retirement evolution of assets. NBER Working Paper No. 15789.

Riley, N. E. (2004). China's population: new trends and challenges. Population Bulletin, 59(2), 1-36.

Waite, L., \& Gallagher, M. (2000). The case for marriage: Why married people are happier, healthier, and better off financially. New York: Doubleday.

Wang, H., Du, S., Zhai, F., \& Popkin, B. M. (2007). Trends in the distribution of body mass index among Chinese adults, aged 20-45 years (1989-2000). International Journal of Obesity, 31, 272-278.

Wang, L., Kong, L., Wu, F., Bai, Y., \& Burton, R. (2005). Preventing chronic diseases in China. Lancet, 366, 1821-1824. 